\title{
UV/Vis Investigation of the Polymerization Center of the Phillips Catalyst
}

\author{
BERND REBENSTORF
}

Division of Inorganic Chemistry 1, Chemical Center, University of Lund, Box 124, S-221 00 Lund 7, Sweden

UV/Vis diffuse reflectance spectra have been recorded of the chromium(II)/silica gel system with low chromium concentration $(0.074 \%)$ after polymerization of $\mathrm{C}_{2} \mathrm{H}_{4}$ at $373 \mathrm{~K}$. From the decrease of the $\mathrm{UV}$ band on the $\mathrm{CO}$ (at $10^{5} \mathrm{~Pa}$ ) complex with the chromium(II) surface ion at $34000 \mathrm{~cm}^{-1}$, it was estimated that roughly $50 \%$ of all chromium is polymerization active at this concentration. The difference spectra of the polymerization active chromium show two bands at 16000 and $31500 \mathrm{~cm}^{-1}$ with absorbed $\mathrm{CO}$ or $\mathrm{C}_{2} \mathrm{H}_{4}$. After removing $\mathrm{CO}$ or $\mathrm{C}_{2} \mathrm{H}_{4}$ by evacuation, a difference spectrum with four bands at $13500,27500,31500$ and $35700 \mathrm{~cm}^{-1}$ was obtained. These bands are interpreted as arising from a chromium(III) surface compound formed by reaction of the chromium(II) with $\mathrm{C}_{2} \mathrm{H}_{4}$ and thus creating the $\mathrm{Cr}-\mathrm{C}$ bond, which is essential for the polymerization active center of the Phillips catalyst.

Recent investigations on the chromium/silica gel system for the polymerization of ethylene (Phillips catalyst ${ }^{1}$ ) have shown that two different catalytic centers exist, either with chromium(II) or with chromium(III). ${ }^{2-7}$ It was found that chromium(III) on silica gel is over a hundred times more active in the polymerization of ethylene than chromium(II). ${ }^{7}$

Nevertheless, on the basis of ESCA measurements ${ }^{8}$ and the determination of turnover numbers ${ }^{7}$ it was concluded that chromium(II) on silica gel is most likely the catalytically active center of the Phillips catalyst. However, because chromium(III) on silica gel has a much higher activity, relatively small amounts of this species can improve the performance of the Phillips catalyst considerably.

For the Phillips catalyst ${ }^{9}$ and the chromium(II) on silica gel ${ }^{7}$ it was found that with low chromium concentration the ratio of the polymerization active chromium to the overall chromium is strongly improved, so that at $0.07 \%$ chromium per silica gel roughly $50 \%$ of all chromium is active. ${ }^{7}$ This ratio is sufficient for an investigation of the conversion of the chromium(II) (without a $\mathrm{Cr}-\mathrm{C}$ bond) to the polymerization species (with the $\mathrm{Cr}-\mathrm{C}$ bond). While other investigation methods like ESCA or IR spectroscopy are difficult to use in the case of low chromium concentrations, UV/Vis diffuse reflectance spectroscopy has such a good signal to noise ratio, that difference spectra can be used successfully on such samples.

\section{EXPERIMENTAL}

The chromium content of all samples was $0.074 \%$ (aftere heating to $1073 \mathrm{~K}$, after drying at $393 \mathrm{~K}: 0.056 \%$ ). Chromium was analyzed by colorimetric determination. ${ }^{10}$ The silica gel 
("Merck 7733") was impregnated with chromic acid. The samples were heated to $1073 \mathrm{~K}$ in vacuum and $\mathrm{O}_{2}$ intermittently and reduced to chromium(II) with $\mathrm{CO}$ at $643 \mathrm{~K}$. Three different samples were investigated: 1) The chromium(II) on silica gel was treated with $\mathrm{C}_{2} \mathrm{H}_{4}$ at $373 \mathrm{~K}$ and $66 \mathrm{kPa}$ pressure, so that only $30 \%$ of the maximum possible amount of polyethylene was formed. 2) The chromium(II) on silica gel was reacted with $\mathrm{C}_{2} \mathrm{H}_{4}$ at room temperature for five minutes. 3) The standard chromium(II) on silica gel sample.

The samples were filled under nitrogen into cylindrical quartz tubes with Schlenk attachment. The diffuse reflectance spectra were recorded on a Hitachi (Perkin-Elmer) UV/Vis/NIR spectrophotometer 330 with an integrating sphere. The spectra were stored in a Perkin-Elmer IR data station 3500, transferred to a Tektronix 4051/4662 table computer and recalculated according to the Kubelka-Munk function. ${ }^{11}$

In order to show at the same time in the figures the $d-d$ bands (between 4000 and 26000 $\mathrm{cm}^{-1}$ ) and the at least ten times more intense charge transfer bands (between 30000 and $50000 \mathrm{~cm}^{-1}$ ), the scale of the reflectivity (recalculated according to the Kubelka-Munk function) was changed at $26000 \mathrm{~cm}^{-1}$ from $0-1.5$ to $0-15$. Sharp bands at $4700,5900,7100$ and $8200 \mathrm{~cm}^{-1}$ are first overtones or combination vibrations from stretching vibrations of $\mathrm{O}-\mathrm{H}, \mathrm{Si}-\mathrm{O}$ or $\mathrm{C}-\mathrm{H}$ bonds.

\section{RESULTS}

Figs. 1. and 2 show the diffuse reflectance spectra of sample 1 (polymerization of $\mathrm{C}_{2} \mathrm{H}_{4}$ at $373 \mathrm{~K}$ ). The evacuated sample (spectrum A, Fig. 1, peaks at 13300,40000 and $47500 \mathrm{~cm}^{-1}$ ) reacts only very weakly with $\mathrm{N}_{2}$ (spectrum $B$, peak shift to $13500 \mathrm{~cm}^{-1}$ ). When treated with $C O\left(10^{5} \mathrm{~Pa}\right)$, however, a strong reaction is observed (spectrum $C$, peaks at 19000 and 33800 $\mathrm{cm}^{-1}$ ). This adsorbed $\mathrm{CO}$ can be removed by vacuum to a high extent (spectrum D, Fig. 1, peaks at 14000,38500 and $\left.47500 \mathrm{~cm}^{-1}\right)$. It should be noticed that the absorbed $\mathrm{CO}\left(10^{5} \mathrm{~Pa}\right)$ shows a strong band in the UV region at $33800 \mathrm{~cm}^{-1}$. This band will be used later to estimate the percentage of the polymerization active chromium.

On reaction with $\mathrm{C}_{2} \mathrm{H}_{4}\left(10^{5} \mathrm{~Pa}\right)$ the spectrum changes again (spectrum $\mathrm{A}$, Fig. 2, peaks at $16300,32000,35500$ and $48000 \mathrm{~cm}^{-1}$ ). The chromium(II) surface compound and the polymerization center are destroyed by $\mathrm{O}_{2}$ (spectrum B, Fig. 2, peaks at 11000,16700 , 31000 and $41000 \mathrm{~cm}^{-1}$ ).

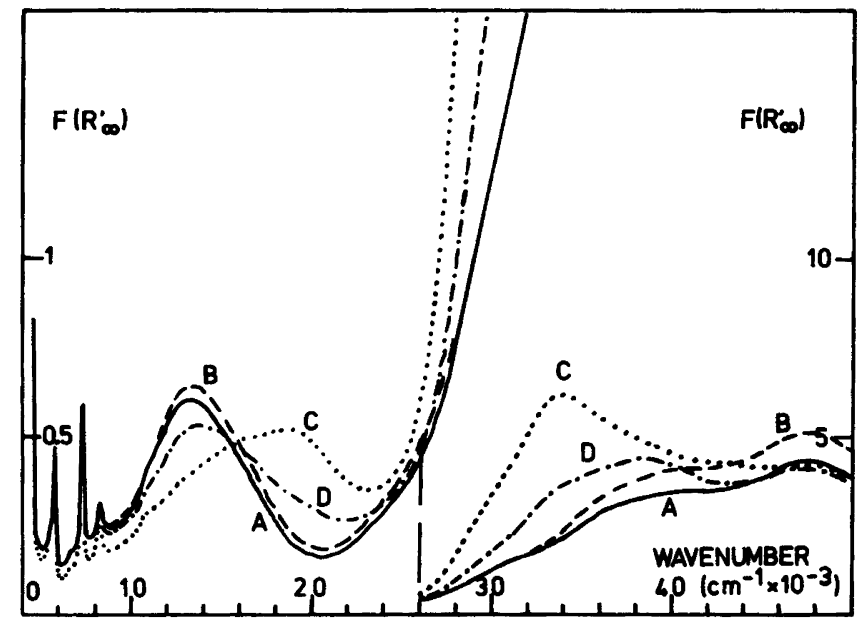

Fig. 1. Diffuse reflectance spectra of chromium(II) on silica gel after polymerization of $\mathrm{C}_{2} \mathrm{H}_{4}$ at $373 \mathrm{~K}$. Spectrum A: vacuum, B: $\mathrm{N}_{2}, 10^{5} \mathrm{~Pa}, \mathrm{C}$ : $\mathrm{CO}, 10^{5} \mathrm{~Pa}, \mathrm{D}: \mathrm{CO}, 10 \mathrm{~Pa}$. 


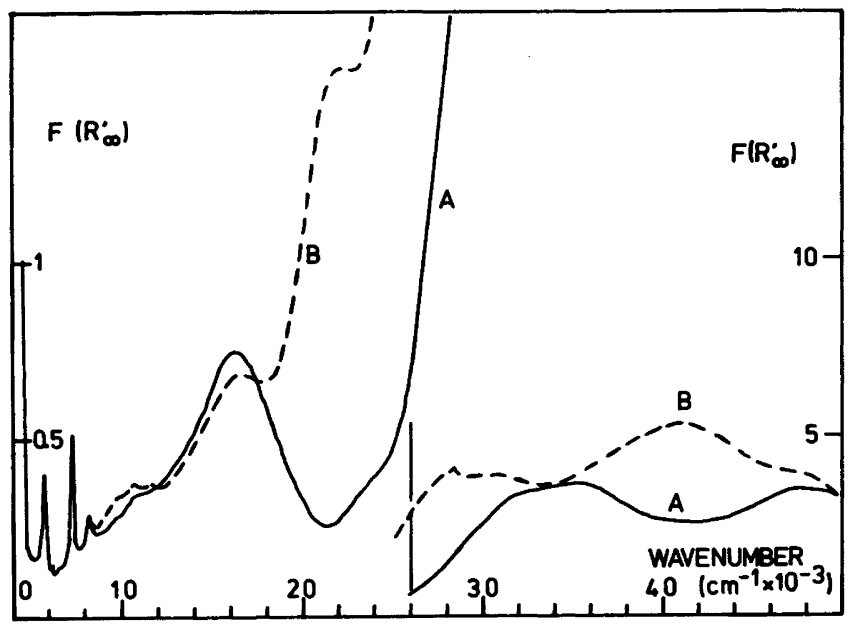

Fig. 2. Diffuse reflectance spectra as in Fig. 1, but spectrum $\mathrm{A}: \mathrm{C}_{2} \mathrm{H}_{4}, 10^{5} \mathrm{~Pa}, \mathrm{~B}: \mathrm{O}_{2}, 10^{5} \mathrm{~Pa}$.

The above spectra from the polymerization experiment will now be compared with those from a standard chromium(II) on silica gel sample ${ }^{13}$ (Fig. 3 and 4). Generally, all spectra from the standard chromium(II) are more intense. This is partly due to a larger specific volume of sample 1 , which causes also the first overtone vibration of the $\mathrm{OH}$ groups at 7000 $\mathrm{cm}^{-1}$ to be weaker for sample 1 . In order to reach the same intensity for this vibration the polymerization sample has to be multiplied with 1.4 .

The second difference that can be noticed is that also the reactions with complexing gases are weaker. The change from the evacuated sample (spectrum A, Fig. 3, peaks at 12000 , 31000,43000 and $47300 \mathrm{~cm}^{-1}$ ) to that with $\mathrm{N}_{2}$ (spectrum $B$, peaks at 13500,43000 and $\left.47600 \mathrm{~cm}^{-1}\right)$ or $\mathrm{CO}\left(10 \mathrm{~Pa}\right.$, spectrum $\mathrm{D}$, peaks at $14000,19500,38000$ and $\left.48000 \mathrm{~cm}^{-1}\right)$ is

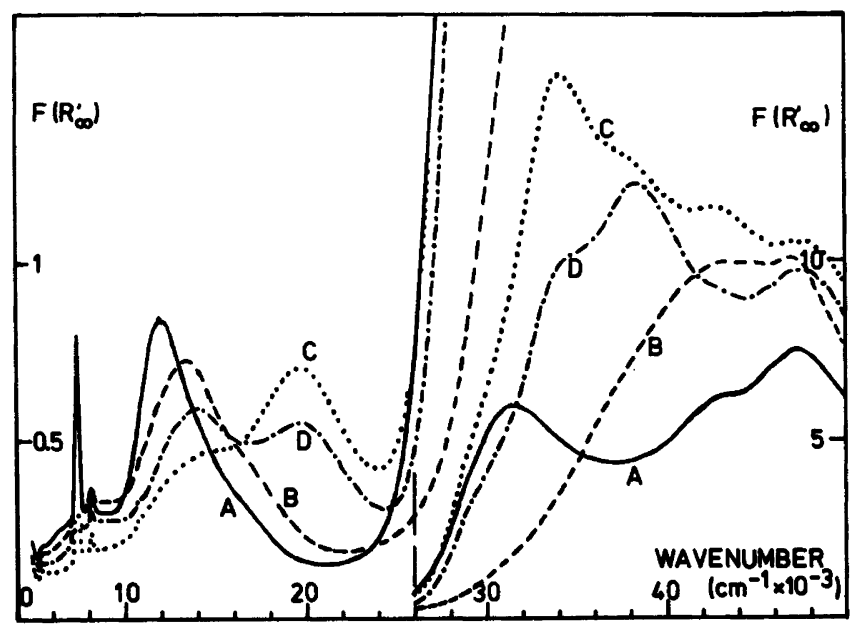

Fig. 3. Diffuse reflectance spectra of standard chromium(II) on silica gel. Spectra A, B, C, $\mathrm{D}$ as in Fig. 1.

Acta Chem. Scand. A 39 (1985) No. 2 


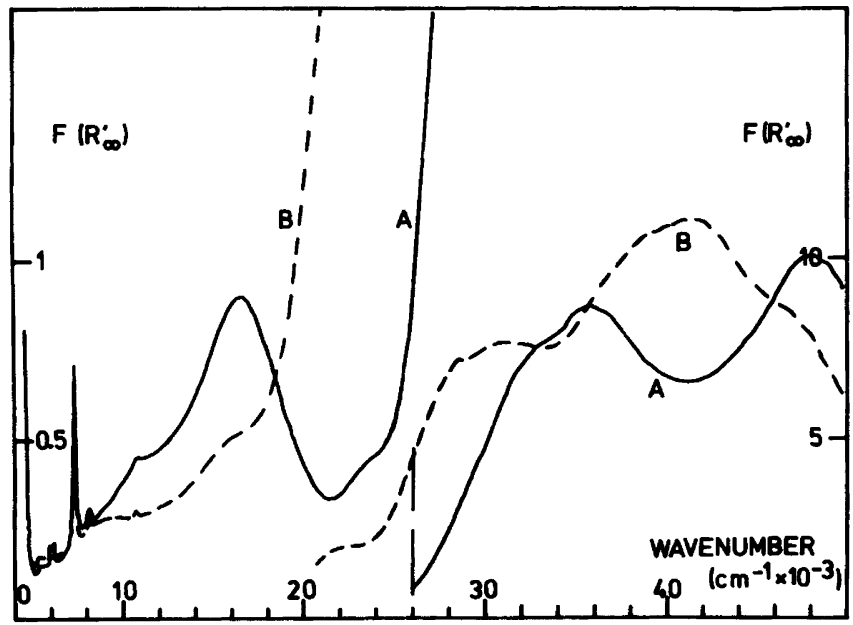

Fig. 4. Diffuse reflectance spectra of standard chromium(II) on silica gel. Spectra A and B as in Fig. 2.

more strongly observed in the spectra of the standard chromium(II) than in those from sample 1 (polymerization with $\mathrm{C}_{2} \mathrm{H}_{4}$ at $373 \mathrm{~K}$ ). $\mathrm{CO}$ adsorbed at $10^{5} \mathrm{~Pa}$ on the standard chromium(II) surface compound has peaks (or shoulders) at 14000, 19500, 33700, 38000, 42000 and $48000 \mathrm{~cm}^{-1}$ (spectrum $\mathrm{C}$ in Fig. 3). The spectrum of $\mathrm{C}_{2} \mathrm{H}_{4}$ adsorbed on the chromium(II) standard is now very similar to that on polymerization sample 1 (spectrum $\mathrm{A}$ in Fig. 4, peaks at 16300,35800 and $48000 \mathrm{~cm}^{-1}$ ). The same is valid also for the spectrum after reaction of chromium(II) with $\mathrm{O}_{2}$ (spectrum B in Fig. 4, peaks (or shoulders) at 9400 , $16000,22000,31000$ and $41000 \mathrm{~cm}^{-1}$ ).

The weakening of the reactivity in the above spectra from the two samples is most likely caused by the formation of the polymerization species. $\mathrm{C}_{2} \mathrm{H}_{4}$ adsorbed on inactive

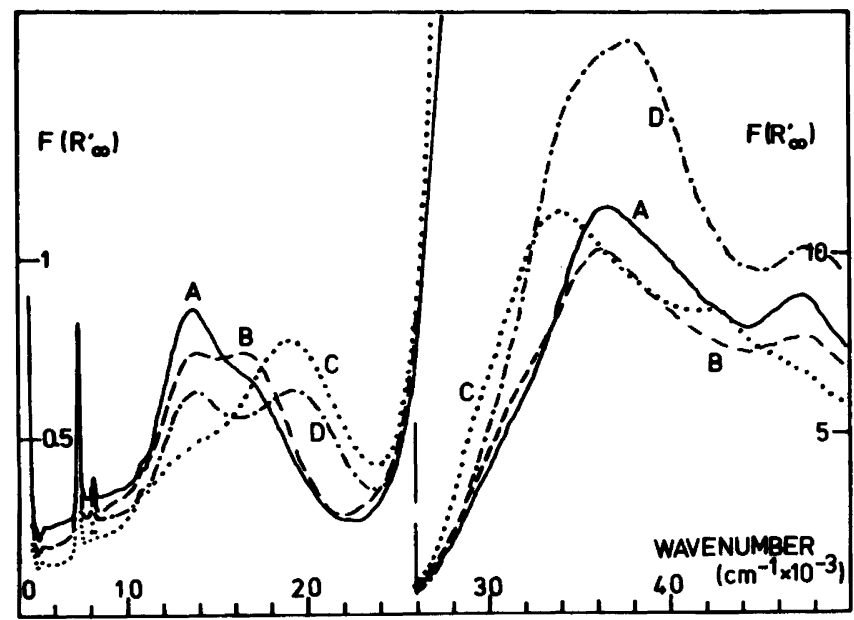

Fig. 5. Diffuse reflectance spectra of chromium(II) on silica gel after contact with $\mathrm{C}_{2} \mathrm{H}_{4}$ at room temperature (for five minutes). Spectra as in Fig. 1. 


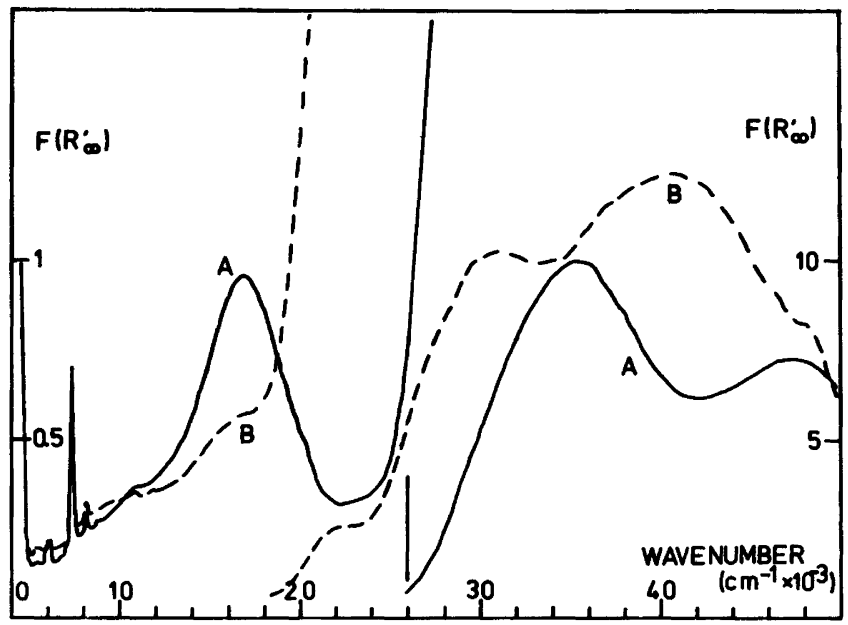

Fig. 6. Diffuse reflectance spectra of chromium(II) on silica gel after contact with $\mathrm{C}_{2} \mathrm{H}_{4}$ at room temperature. Spectra as in Fig. 2.

chromium(II) and $\mathrm{CH}_{2}$ groups from the polymer may, however, contribute to the above differences in the spectra. In order to clarify this, spectra of sample 2 (short contact with $\mathrm{C}_{2} \mathrm{H}_{4}$ at room temperature) are shown in Figs. 5 and 6. From the UV part of the spectra of sample 2, which have similar intensity as those of the standard sample, it becomes clear that adsorbed $\mathrm{C}_{2} \mathrm{H}_{4}$ does not weaken these bands intensity. From the relatively big difference between spectra $A$ (vacuum) and $B\left(N_{2}, 10^{5} \mathrm{~Pa}\right)$ in Fig. 5 as compared with spectra $A$ and $B$ in Fig. 1, it can be concluded that more than just an adsorption of $\mathrm{C}_{2} \mathrm{H}_{4}$ has occurred with sample 1. One should also notice that the shoulder at 16000 or $16300 \mathrm{~cm}^{-1}$ in spectrum $A$ (Figs. 4 and 6, respectively) is converted into a band with a peak at $16700 \mathrm{~cm}^{-1}$ in the case of the polymerization sample (spectrum A, Fig. 2).

The difference between vacuum and adsorbed $\mathrm{N}_{2}$ is, as was already noticed above, very small for the spectra of sample 1 (polymerization at $373 \mathrm{~K}$ ), if compared with the difference for a standard chromium(II) sample. The cause of this small difference is most likely an interaction of the produced polyethylene with the catalytically inactive chromium(II) surface compound. This interaction from the polymer, which competes successfully with $\mathrm{N}_{2}$ for complexing the chromium(II), is however, weaker than the adsorption of $\mathrm{CO}$ or $\mathrm{C}_{2} \mathrm{H}_{4}$. We have no comparison spectrum for the interaction with the polymer to subtract from the spectra of sample 1 . Therefore, we start the series of difference spectra with the spectra of $\mathrm{CO}$ at $10^{5} \mathrm{~Pa}$.

Fig. 7 shows the three reflectance spectra of sample 1, 2 and 3 (spectra A, B and C). Spectrum A from Fig. 1 (here spectrum D) will be used as a baseline for the CO UV band at $34000 \mathrm{~cm}^{-1}$, because it shows the lowest reflectivity at this wavenumber. Spectra A and D in Fig. 7 have been multiplied by 1.4 (see above). By comparing the intensity of the CO UV band at $34000 \mathrm{~cm}^{-1}$ in spectrum $C$ to the one in spectrum $A$, both with respect to the baseline in spectrum $D$, the intensity of the band in spectrum $A$ is found to be only $46 \%$ of that in spectrum $\mathrm{C}$. The decrease, $54 \%$, corresponds to the percentage of polymerization active centers formed. This is in good agreement with results from a previous investigation, ${ }^{7}$ where roughly $50 \%$ was found. In the case of spectrum B (from sample 2) a percentage of Acta Chem. Scand. A 39 (1985) No. 2 


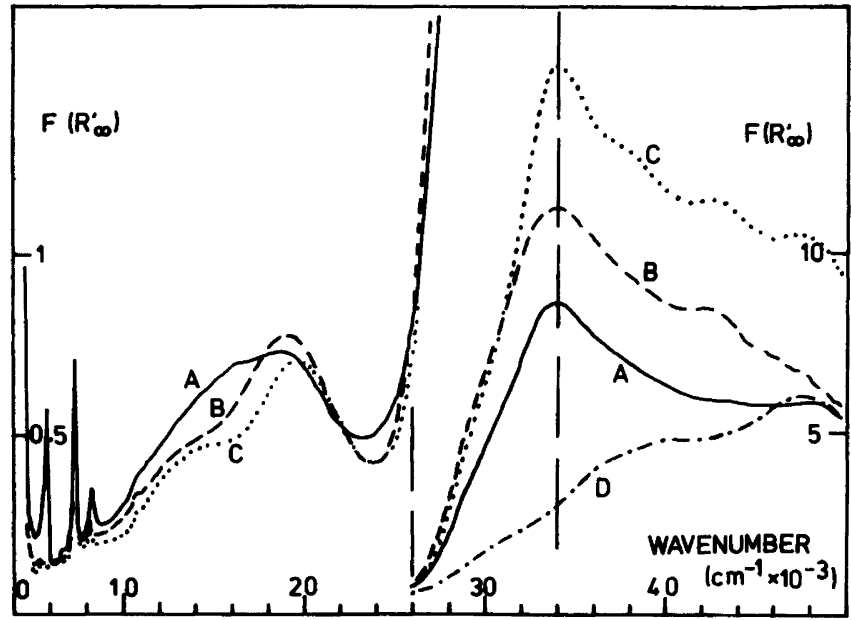

Fig. 7. Diffuse reflectance spectra from the above three chromium(II) on silica gel samples with CO $\left(10^{5} \mathrm{~Pa}\right)$. The decrease of the UV and at $34000 \mathrm{~cm}^{-1}$ is used to estimate the percentage of polymerization active chromium(II).

$32 \%$ polymerization active chromium was calculated in the same way. This means that on short contact with $\mathrm{C}_{2} \mathrm{H}_{4}$ at room temperature, only half the possible number of chromium(II) surface ions is converted to the polymerization active center as would be possible at $373 \mathrm{~K}$.

With the above result of $50 \%$ we now know how much chromium(II) is not converted in Figs. 1 and 2. This inactive chromium(II) should show the same reflectance spectra as in Fig. 3 and 4 for $\mathrm{CO}$ and $\mathrm{C}_{2} \mathrm{H}_{4}$ and can now be subtracted for the first time with safety. So, spectrum $C$ in Fig. 7 was divided by two and subtracted from spectrum $A$ in Fig. 7. The results is shown in Fig. 8 as spectrum A. Only two peaks at 16000 and $31500 \mathrm{~cm}^{-1}$ are

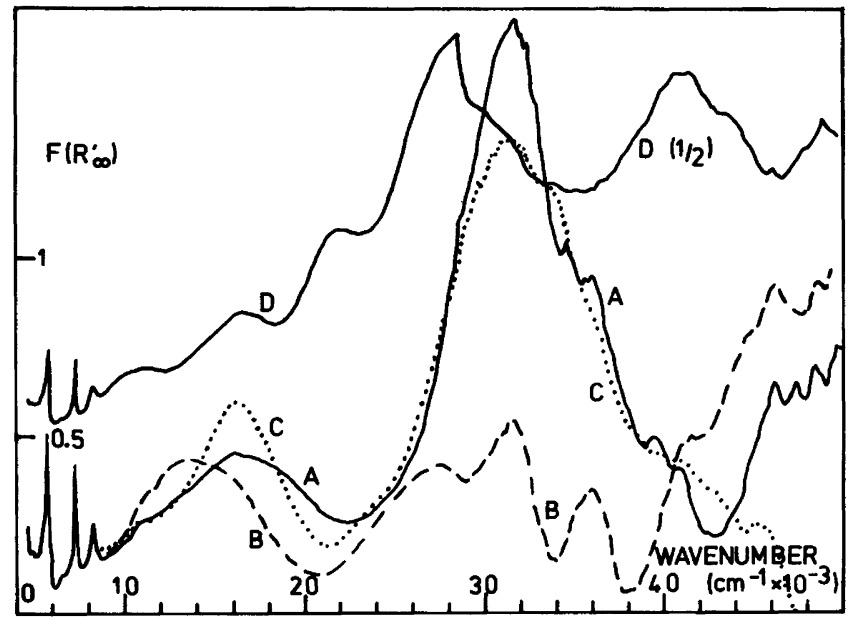

Fig. 8. Difference spectra of the polymerization active chromium surface compound (see text). Spectrum A: $\mathrm{CO}, 10^{5} \mathrm{~Pa}, \mathrm{~B}$ : vacuum, C: $\mathrm{C}_{2} \mathrm{H}_{4}, 10^{5} \mathrm{~Pa}, \mathrm{D}: \mathrm{O}_{2}, 10^{5} \mathrm{~Pa}$. 
obtained in the first spectrum of the polymerization active chromium after initiation of the polymerization. Two shoulders at 19300 and $35000 \mathrm{~cm}^{-1}$ may indicate that the bands of the polymerization inactive chromium(II) are not subtracted completely.

The same subtraction was performed with the spectra CO (vacuum) (evacuation after $C O$ adsorption: spectrum D in Fig 3 subtracted from spectrum D in Fig. 1). The result is spectrum B in Fig. 8. Here we have four peaks at $13500,27500,31500$ and $35700 \mathrm{~cm}^{-1}$. The band at $31500 \mathrm{~cm}^{-1}$ may be an indication, that not all adsorbed $\mathrm{CO}$ has been removed from the polymerization active chromium(II) by evacuation.

The third difference spectrum is calculated from the spectra with adsorbed $\mathrm{C}_{2} \mathrm{H}_{4}\left(10^{5}\right.$ $\mathrm{Pa}$ ). The resulting spectrum $\mathrm{C}$ in Fig. 8 is quite similar to that calculated from the spectra with adsorbed $\mathrm{CO}\left(10^{5} \mathrm{~Pa}\right)$ with two peaks at 16000 and $31500 \mathrm{~cm}^{-1}$. We can conclude that the polymerization active chromium surface species adsorbs $\mathrm{CO}$ and $\mathrm{C}_{2} \mathrm{H}_{4}$ alike and that, as a result of this reaction, its two d-d bands are shifted to higher wavenumbers by 2200 or 4000 $\mathrm{cm}^{-1}$, respectively. In addition, the intensity of the band at 27500 or $31500 \mathrm{~cm}^{-1}$ is increased by a factor of 3 to 4 on reaction with $\mathrm{CO}$ and $\mathrm{C}_{2} \mathrm{H}_{4}$. It should be noticed, that in all three spectra, the wavenumber position of the second band is nearly exactly two times that of the first band.

The fourth spectrum (D in Fig. 8) is the difference spectrum calculated from the spectra with $\mathrm{O}_{2}\left(10^{5} \mathrm{~Pa}\right)$. In order to show this spectrum in the scale of Fig. 8 it was divided by two. Here we have five peaks at $11000,16500,22000,28500$ and $41000 \mathrm{~cm}^{-1}$, which arise from different oxidation products from chromium(II) and the polymerization active chromium surface compound. Both surface compounds are destroyed by oxygen.

\section{DISCUSSION}

The chromium(II) surface compound on silica gel has been investigated ever since Krauss and Stach $^{2}$ stated, in 1968 , that this coordinatively unsaturated surface compound is the polymerization center of the Phillips catalyst. It is well known that the chromium(II) in this compound is only two-coordinated (under vacuum) with two oxygen ligands. ${ }^{12-14} \mathrm{~A}$ simple model of this surface compound is structure $A$ in the scheme. In order to become the polymerization center, this coordinatively unsaturated chromium(II) compound has to get a chromium-carbon bond as shown in the scheme by structure B. During this conversion the chromium(II) is formally oxidized to chromium(III). In order to be able to polymerize

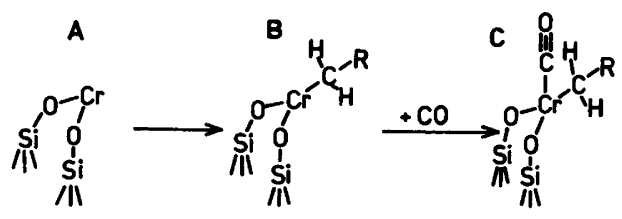

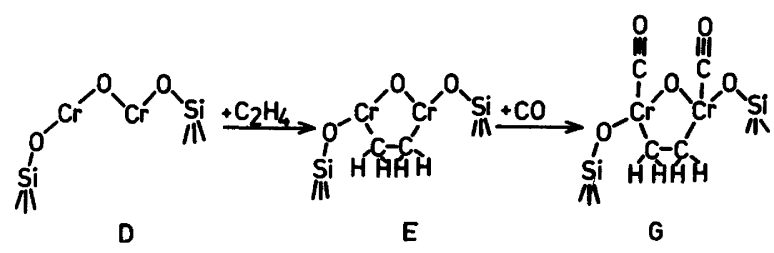

Acta Chem. Scand. A 39 (1985) No. 2 
ethylene a free coordination site must be available. In structure $\mathrm{C}$ this free coordination site is occupied by $\mathrm{CO}$, which can be replaced by $\mathrm{C}_{2} \mathrm{H}_{4}$ without difficulty.

Replacing the organic rest $\mathrm{R}$ in structure $\mathrm{B}$ by a methyl group $\left(-\mathrm{CH}_{3}\right)$ produces a severe problem for an initiation of the polymerization by a reaction of structure $A$ with $\mathrm{C}_{2} \mathrm{H}_{4}$. One additional hydrogen atom is neccessary. No evidence of a carbene mechanism was found. ${ }^{17}$ The problem can be solved, however, very easily by using a dinuclear surface compound ${ }^{18}$ as shown in structure $\mathrm{D}$ in the scheme. One ethylene molecule produces in this case two chromium-carbon bonds and no additional hydrogen atom has to be created from nothing. The chromium is again oxidised formally to chromium(III) and can adsorb $\mathrm{CO}$ or $\mathrm{C}_{2} \mathrm{H}_{4}$ (structure $\mathrm{E}$ and $\mathrm{G}$, respectively).

In order to determine how many bands at which position the polymerization active chromium(III) surface compound should show, a comparison with octahedral chromium(III) complexes gives three bands, for example at 18000,24600 and $36600 \mathrm{~cm}^{-1}$ $\left(\mathrm{KCr}\left(\mathrm{SO}_{4}\right)_{2} \cdot 12 \mathrm{H}_{2} \mathrm{O}\right) .{ }^{15}$ These three bands are interpreted as transitions from the ${ }^{4} A_{2 g}$ ground state to the ${ }^{4} T_{2 g},{ }^{4} T_{1 g}$ and ${ }^{4} T_{1 g}$ excited states. The last two excited states have the same designations. This means that they never cross and that the second transition has not exactly two times the energy of the first one. The first two bands from our example above agree only roughly with the first two bands from spectra $A\left(16000,31500 \mathrm{~cm}^{-1}\right), B(13500$, $\left.27500 \mathrm{~cm}^{-1}\right)$ and $C\left(16000,31500 \mathrm{~cm}^{-1}\right)$ from Fig. 8 .

We have, however, in our case a different configuration than octahedral; most likely trigonal planar for the polymerization active chromium(III) without $\mathrm{CO}$ or $\mathrm{C}_{2} \mathrm{H}_{4}$ and trigonal pyramical for that with adsorbed $\mathrm{CO}$ and $\mathrm{C}_{2} \mathrm{H}_{4}$. We try now to fit the bands from spectrum B, Fig. 8 to ligand field energy diagrams for $d^{3}$ electronic systems with trigonal symmetry. ${ }^{16}$ Fitting our first band to the first transition in the diagram we get a DQ value of $1300 \mathrm{~cm}^{-1}$. The groud state is ${ }^{4} A_{2} 2\left({ }_{3}^{4} F\right)$ and the excited states are ${ }^{4} A_{1} 1\left({ }_{3}^{4} F\right),{ }^{4} E 1\left({ }_{3}^{4} F\right)$, ${ }^{4} A_{2} 1\left({ }_{3}^{4} F\right),{ }^{4} E 2\left({ }_{3}^{4} F\right),{ }^{4} A_{2} 1\left({ }_{3}^{4} P\right)$ and ${ }^{4} E 1\left({ }_{3}^{4} P\right)$. There are six transitions with 13500,16000 , $19200,28000,33000$ and $40000 \mathrm{~cm}^{-1}$. Of these six transitions we can point out five (together with the first band) in spectrum B in Fig. 8. The transition at $19200 \mathrm{~cm}^{-1}$ is at best a weak shoulder and the band in the spectrum at $31500 \mathrm{~cm}^{-1}$ was interpreted above.

Now fitting the band at $16000 \mathrm{~cm}^{-1}$ from the spectra $A$ and $C$ in Fig. 8, we get a DQ value of $15300 \mathrm{~cm}^{-1}$ and transitions at $16000,18500,21800,31000,35000$ and $46000 \mathrm{~cm}^{71}$. Again the bands at 18500 and $21800 \mathrm{~cm}^{-1}$ are shoulders together with that at $35000 \mathrm{~cm}^{-1}$. Only one band at $46000 \mathrm{~cm}^{-1}$ is missing in spectrum $\mathrm{C}$. Although the above assignments are tentative, they show that the spectra of the polymerization active chromium can be interpreted as bands from a chromium(III) complex with trigonal symmetry.

Acknowledgement. The author thanks the Swedish Board for Technical Development for financial support.

\section{REFERENCES}

1. Clark, A., Hogan, J.P., Banks, R.L. and Lanning, W.C. Ind. Eng. Chem. 48 (1956) 1152.

2. Krauss, H.L. and Stach, H. Inorg. Nucl. Chem. Lett. 4 (1968) 393.

3. Przhevalskaya, L.K., Shvets, V.A. and Kazansky, V.B. J. Catal. 39 (1975) 383.

4. Naumann, D., Diss. Freie Universitet Berlin, West Berlin 1979.

5. Beck, D.D. and Lunsford, J.H. J. Catal. 68 (1981) 121.

6. Groeneveld, C., Wittgen, P.P.M.M., Lavrijsen, J.P.M. and Schuit, G.C.A. J. Catal. 82 (1983) 77. 
7. Rebenstorf, B. Z. Anorg. Allg. Chem. 513 (1984) 103.

8. Merryfield, R., McDaniel, M. and Parks, G. J. Catal. 84 (1982) 348.

9. Hogan, J. P. J. Polym. Sci. Part A 1, 8 (1970) 2637.

10. Hierl, G. and Krauss, H.L. Z. Anorg. Allg. Chem. 401 (1973) 263.

11. Stone, F. S. In Bonnelle, J.P., Delmon, B. and Derouane, E. and Reidel, D., Eds., Surface Properties and Catalysis by Non-Metals, Dordrecht 1983, p. 237.

12. Hierl, G. and Krauss, H.L. React. Kinet. Catal. Lett. 3 (1975) 47.

13. Krauss, H.L. and Naumann, D. Z. Anorg. Allg. Chem. 446 (1978) 23.

14. Krauss, H.L. and Westphal, U. Z. Naturforsch. Teil B 33 (1978) 1278.

15. Schläfer, H.L. and Gliemann, G. Einführung in die Ligandenfelftheorie, Akademische Verlagsgesellschaft, Frankfurt am Main 1967, p. 78.

16. König, E. and Kremer, S. Ligand Field Energy Diagrams, Plenum, New York 1977, p. 153.

17. McDaniel, M.P. and Cantor, D.M. J. Polym. Sci., Polym. Chem. Ed. 21 (1983) 1217.

18. Rebenstorf, B. and Larsson, R. J. Mol. Catal. 11 (1981) 247.

Received July 5, 1984. 